\title{
Fluoroscopy Comes to the Rescue in Anaesthesia Management of a Case of Ankylosing Spondylitis
}

\author{
Tanumoy Maulick ${ }^{1}$, Preeti More ${ }^{2}$
}

\section{Abstract}

Introduction: Ankylosing spondylitis is an anaesthetic challenge both from the airway and neuraxial point of view. The success rates as reported in literature while administering neuraxial anaesthesia in such cases are very low. We describe here such a case posted for total hip replacement.

Case Report: A 25 year old male patient was posted for right total hip replacement (THR) due to total arthrodesis of the right hip joint. He had a previous history of left THR done 1.5 yrs back. The patient was unable to sit erect and flexion and extension movements of the spine were painful. Both active and passive movements, were severely restricted due to pain and stiffness, upto only 25-30 degrees in the right hip joint and 45-50 degrees in the left hip joint and this has made him completely bedridden. For the anaesthetic management of this case, we combined fluoroscopy, a commonly used tool in chronic pain practice, into anaesthesia practice by using it for administration of epidural anaesthesia via inter-laminar approach in prone position. The perioperative and post operative course was uneventful.

Conclusion: We conclude that fluoroscopy can be used in realtime as one of the most useful tools while administering neuraxial anaesthesia in difficult spine scenarios.

Keywords: Ankylosing Spondylitis; Neuraxial Anaesthesia; Epidural Anaesthesia; Fluoroscopy; Total Hip Replacement.

\section{Introduction}

Fluoroscopy forms an integral part in various interventions done in orthopaedic and neurosurgeries. The use of C-Arm helps as a guide in chronic pain intervention procedures but it's use in the practice of regional anaesthesia techniques is rare though known [1].

Ankylosing spondylitis (AS) being a chronic inflammatory disease of the axial skeleton and peripheral joint [2] has always been a challenge to the anaesthesiologist for its known association with difficult airway or a seemingly impossible central neuraxial blockade. Videolaryngoscopy and fibreoptic bronchoscopy has been used successfully to secure the airway [3] as central neuraxial blocks may not be easy to perform in such cases.

Here we describe the use of fluoroscopy for the anaesthetic management of a case of total hip replacement (THR) in a patient of Ankylosing Spondylitis.

\section{Case Report}

A 25 year old male patient posted for right THR due to total arthrodesis of the right hip joint. He had a previous history of left THR done 1.5 yrs back under general anaesthesia as attempted central neuraxial block was a failure that time.

The patient was unable to sit erect and flexion and extension movements of the spine were painful. Both active and passive movements, were severely restricted due to pain and stiffness. Hip flexion was upto only 25-30 degrees in the right side and 45-50 degrees in the left side and this had made him completely bedridden. Airway examination was normal with normal neck movements. General and systemic examinations along with the vital parameters were also normal. The patient was on treatment with Hydroxychloroquine and Methotrexate. The blood counts, liver function, renal function, coagulation parameters were normal. The chest radiograph and ECG were normal. Pulmonary function testing showed normal findings (FEV1

${ }^{1}$ Department of Anaesthesia, Ganga Medical Center and Hospital,

Coimbatore, Tamil Nadu, India.

${ }^{2}$ Department of Anaesthesiology, ESIPGIMSR Andheri, Andheri (E),

Mumbai, Maharashtra, India.

Address of Correspondence

Dr. TanumoyMaulick,

Fellow in Regional Anaesthesia, Ganga Medical Center and Hospital,

Coimbatore, Tamil Nadu, India.

Email: tanumoymaulik@gmail.com

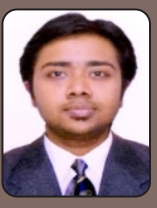

Dr. Tanumoy Maulick

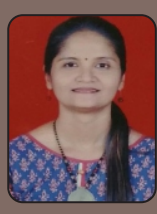

Dr. Preeti More

2021 (C) Journal of Anaesthesia and Critical Care Case Reports| Available on www.jaccr.com | ISSN 2454-7174| DOI: 10.13107/jaccr.2021.v07i01.169

This is an Open Access article distributed under the terms of the Creative Commons Attribution Non-Commercial License (http://creativecommons.org/licenses/by-nc/3.0) which permits unrestricted non-commercial use, distribution, and reproduction in any medium, provided the original work is properly cited.

18 | Journal of Anaesthesia and Critical Care Case Reports | Volume 7 | Issue 1 | January-April 2021 | Page 18 -21 


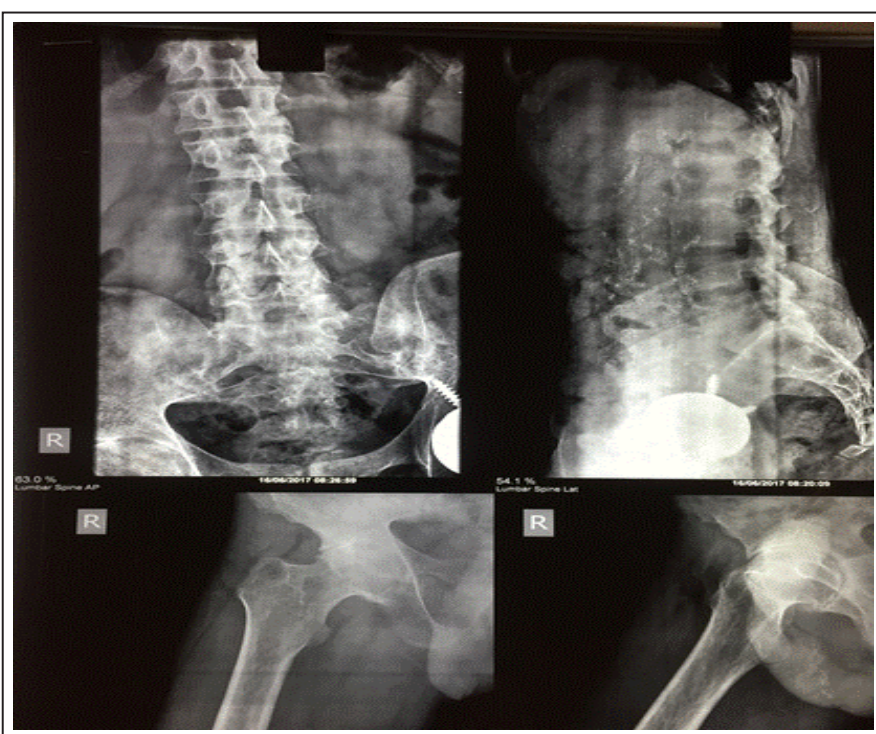

Figure 1: Showing X-Ray of the Lumbar Spine and Hip joints of the patient

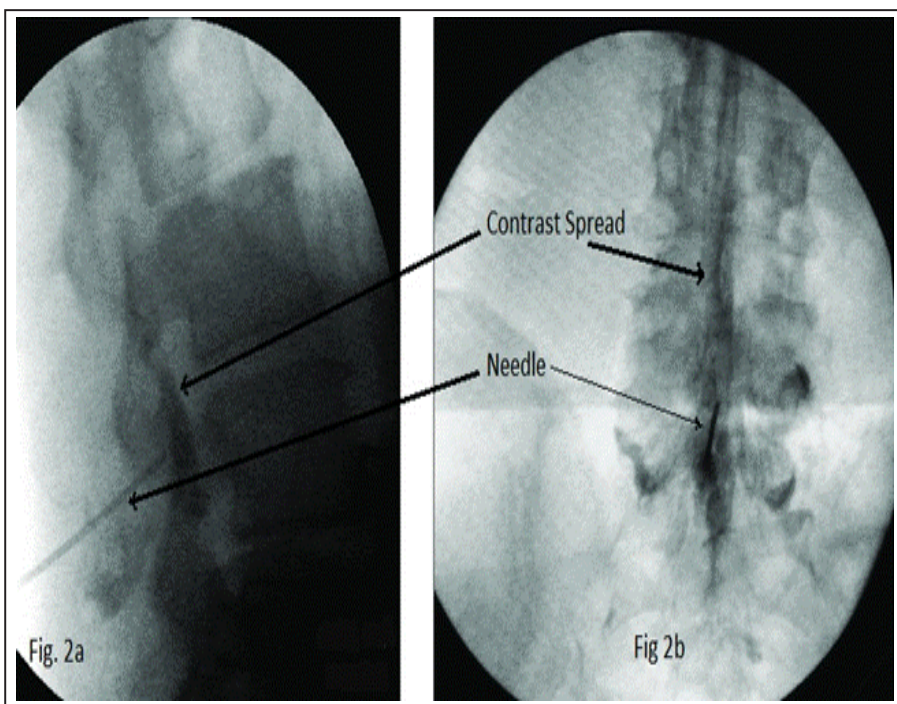

Figure 2a \& 2b: Shows contrast spread in the epidural space, in lateral and AP fluoroscopic projections, respectively

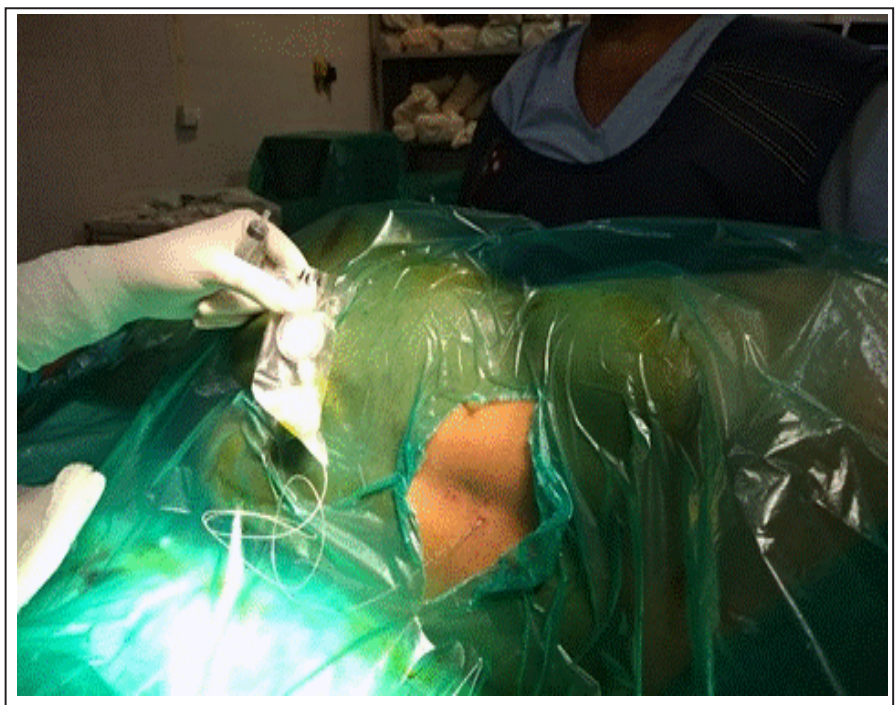

Figure 1: Showing the epidural catheter in situ while turning the patient to supine position was $76 \%$ and $\mathrm{FVC}$ was $81.5 \%$ of the predicted value with no restrictive pattern). The X-ray of lumbar spine (Fig 1) showed diffuse fusion with ligamental calcification of spinal spaces from L2 downwards. Above L2 \& at L5-S1, the interspinous spaces were well defined. Both the old MRI done during previous surgery and the recent bilateral X-ray hip findings show that the right hip joint was grossly destroyed. Also the ligamental calcifications were noted upto the L2 level with disc calcifications.

On the day of surgery, epidural anaesthesia was planned. The procedure was explained to the patient and written informed consent was obtained. Two wide bore accesses were IV access taken in both arms in anticipation of blood loss and need for blood transfusion intraoperatively. Standard ASA recommended monitors were attached including pulse oximetry, NIBP, ECG, Urine output (after induction of anaesthesia) and a skin temperature probe and intravenous fluid was started. The lumbar spine X-ray was referred again and few calcified spots in the L1-2 \& L5-S1 space were noted. We decided to perform epidural placements under fluoroscopic guidance specially as the previous attempt of blind neuraxial block had failed. Also, we did ensure that the difficult airway cart was kept ready in the untoward events of complications of neuraxial blocks, such as high or total spinal blockade.

The patient was made prone with a pillow under the abdomen of the patient to increase the lumbar lordosis and facilitate opening of spinal spaces.

The L5-S1 interspace was identified by squaring of the vertebral endplates under fluoroscopy and inter laminar approach of epidural insertion was planned. The needle entry point was selected a little away from the midline, on the left side, due to the presence of few calcific opacities at the centre of the space. After localizing the entry point, local infiltration with lignocaine $2 \%$ was done under all aseptic precaution. An 18 G Touhy's epidural needle was inserted into the space under tunnel view in a postero-anterior fluoroscopic view. After inserting the epidural needle for few centimetres, lateral view was obtained. Further needle advancements were done in a slow and controlled fashion, only in the lateral view, along with intermittent elicitation of loss of resistance (LOR) technique to saline. Final position was confirmed by finding the Touhy's needle entering the epidural space after crossing the J-line. LOR to saline was elicited. Iodinated contrast media was injected to reconfirm bilateral epidural contrast spread under fluoroscopy. The epidural catheter was inserted and the final position of the catheter tip was confirmed again by contrast injection and fluoroscopic assessment of its spread. The catheter was fixed at $5 \mathrm{~cm}$ inside the epidural space.

The patient was made supine and then Inj Bupivacaine $0.5 \%$ 
$10 \mathrm{ml}$ was injected in a graded dosage to achieve dermatomal block upto T10 level, while maintaining hemodynamic stability. After the dermatomal block level was confirmed, patient was given right lateral position and the surgery started. Intraoperatively, epidural infusion with injection bupivacaine $(0.5 \%)$ was continued at the rate of $5 \mathrm{ml} / \mathrm{hr}$ and a mean arterial pressure of greater than $60 \mathrm{mmHg}$ was maintained by appropriate fluid therapy, blood transfusion and vasopressor therapy as and when needed. Surgery lasted for 1.5 hours and total blood loss was $800 \mathrm{ml}$ which was replaced by one unit of PRBC transfusion.

The epidural catheter was used postoperatively for analgesia with a continuous infusion of Inj bupivacaine $(0.125 \%)$ and Inj Fentanyl $2 \mathrm{mcg} / \mathrm{ml}$ at the rate of $6 \mathrm{ml} / \mathrm{hr}$ with an elastomeric pump for 48 hours and post op physiotherapy was facilitated.

\section{Discussion}

Ankylosing Spondylitis (AS) is an autoimmune seronegative chronic inflammatory disease involving the axial skeleton, in which the inflammatory process starts at the sacro-iliac joint and migrates in a cephalad direction to involve, sometimes, the entire spine. In $90-95 \%$ of cases, AS has an association with HLA B-27 alleles [2]. Due to widespread thickening and calcifications of the axial ligaments, there is stiffening and decreased range of motion of spine and hip joint. There is a variable amount of pain and morning stiffness in these patients that improve with exercise. Bony bridges (syndesmophytes) between vertebrae causes 'bamboo spine' causing difficulty in penetration while performing neuraxial blocks and a difficult airway due to decreased neck movement while administering general anaesthesia. Due to involvement of the costovertebral ligaments, there may be restrictive lung disease. In our patient, the ligamental thickening as evidenced by lumbar spine radiograph showed involvement upto L2-3 level and there was no restriction of neck movement and pulmonary functions. The hip joint movements were painful and restricted.

Neuraxial anaesthesia offers many advantages in patients for THR [2] where it provides excellent anaesthesia and post operative analgesia, decreases blood loss, prevents DVT, avoids airway handling and enhances early recovery and post operative mobilisation and physiotherapy. General anaesthesia carries risk of difficult intubation and postoperative pulmonary dysfunction due to restrictive pulmonary pattern. Central neuraxial blocks are known to be difficult in AS having only few reports of successful neuraxial blocks in patients with AS been available in the literature $[4,5]$. In the largest review of 80 patients over a 10 year period, Schelew et al. planned spinal anaesthesia in only
16 patients out of which they reported success in only 10 patients [6]. A paramedian approach (Taylor's approach when it is done at the level of L5-S1) may be easier because of the calcification of the midline ligaments [7]. However, due to thickening of the ligamentum flavum, threading of the epidural catheter can be easy and there might be less chance of catheter kinking, knotting or migration through intervertebral foramen.

For anaesthetizing our patient, we planned to avoid General Anaesthesia to prevent its complications and decided to give epidural anaesthesia under fluoroscopic guidance considering its benefits and efficacy. We planned to give Epidural in prone position as it was difficult and painful for the patient to sit and lie in lateral position. Using CSE technique would have been difficult as the spinal needle available in the CSE set is of small calibre (27G Whitacre type) and could pose difficulty in showing back flow of CSF spontaneously and on aspiration against gravity in prone position. Also a wide bore spinal needle introduction at a separate space was not an option due to calcification of ligaments. All authors demonstrating spinal anaesthesia in prone position had used a wide bore spinal needle for confirming back flow of $\operatorname{CSF}[8,9,10,11,12]$. According to literature, there is an incidence of incomplete motor block after low dose spinal in prone position due to considerable mobility of the cauda equina in the CSF [11] and its anterior displacement in the prone position rendering the posterior roots (sensory) more susceptible to block than more anterior roots (motor) if a hypobaric solution is used [13, $14]$.

Fluoroscopy guided epidural placement in prone position [15] is quick, simple, safe and an established practice in interventional pain medicine $[16,17]$. Catheters can be placed accurately at the level of appropriate dermatomes as the spinal level determination is accurate under radiography. Lateral view provide greater safety [16] as the needle tip can be visualised clearly and accidental dura puncture can be avoided. Also the catheter tip level can be ascertained by injecting 0.5-1 ml of contrast agent. Diagnosis of accidental intravascular placement (instant disappearance of the contrast agent) or catheter migration into the CSF (dilution and slow disappearance of contrast agent) can be done easily and corrected promptly. Also any midline calcification can be seen under fluoroscopy and accordingly needle placement can be manipulated and smooth advancement of needle can be planned such as inserting the needle to the medial or lateral side of the spinous process and directing it towards the midline [16], as was done in this case. Epidural anaesthesia further helped in maintaining post operative analgesia and assisting the patient to undergo painless physiotherapy in the post operative period. 


\section{Conclusion}

Fluoroscopy can be used as a dependable tool in challenging cases with greater propensity of achieving success in placement of neuraxial blocks and also for the successful anaesthetic management of difficult spine cases as in Ankylosing Spondylitis.

\section{References}

1. Channabasappa SM, Dharmappa S, Pandurangi R. Fluoroscopy guided transforaminal epidural anesthesia in ankylosing spondylitis. Saudi $J$ Anaesth. 2016 Jan-Mar;10(1):101-3. doi: 10.4103/1658354X.169486. PMID: 26955319; PMCID: PMC4760027.

2. Woodward LJ, Kam PC. Ankylosing spondylitis: Recent developments and anaesthetic implications. Anaesthesia 2009;64:540-8.

3. Dave N, Sharma RK. Temporomandibular joint ankylosis in a case of ankylosing spondylitis- anaesthetic management. Indian J Anaesth 2004;48:54-6.

4. Sivrikaya GU, Hanci A, Dobrucali H, Yalcinkaya A. Cesarean section under spinal anesthesia in a patient with ankylosing spondylitis. Middle East J Anesthesiol 2010;20:865-8.

5. Goyal R, Singh S, Shukla RN, Singhal A. Management of a case of ankylosing spondylitis for total hip replacement surgery with the use of ultrasoundassisted central neuraxial blockade. Indian J Anaesth 2013;57:69-71.

6. Schelew BL, Vaghadia H. Ankylosing spondylitis and neuroaxial anaesthesiaa 10year review. Can J Anaesth 1996;43:65-8.

7. Jindal P, Chopra G, Chaudhary A, Rizvi AA, Sharma JP. Taylor's approach in an ankylosing spondylitis patient posted for percutaneous nephrolithotomy: A challenge for anaesthesiologists. Saudi J Anaesth 2009;3:87-90.

8. Laakso E, Pitkänen M, Kyttä J, Rosenberg PH. Knee chest vs. horizontal side position of spinal anesthesia in patients undergoing surgery. Br J Anaesth 1997;79(5): 609-611.

9. WolffCR, Charles WU. The prone jackknife position for the administration of spinal anesthesia. Anesthesia analgesia 1963; 42(3):375-378.

10. Imbelloni Luiz Eduardo, Vieira Eneida Maria, Gouveia Marildo Assunção,
Cordeiro José Antônio. Restricted dorsal spinal anesthesia for ambulatory anorectal surgery: a pilotstudy. Rev Bras Anestesiol 2004;54(6):774-780.

11. Medhat H, Ellen G, Vance W. Fluoroscopy-guided, small-dose spinal anesthesia for kyphoplasty: a collaborative effort between the anesthesiologist and interventional radiologist. Anesthesia analgesia 2008;106(4):1329-30.

12. Rajendra P, Priti D, Sudha H. Subarachnoid Block in Prone Position for Giant Gluteal Neurofibroma. J Anesth Crit Care Open Access 2016;4(2): 00131.DOI: 10.15406/jaccoa.2016.04.00131.

13. Gouveia MA, Imbelloni LE. Plain anaesthetic agent solutions in the prone position. Anaesthesia 2009;64(7). https://doi.org/10.1111/j.13652044.2009.05977.x

14. Cuvas $O, G u l e c H$, Karaaslan $M$, et al. The use of low dose plain solutions of local anaesthetic agents for spinal anaesthesia in the prone position: bupivacaine compared with levobupivacaine. Anaesthesia 2009; 64: 14-8.

15. Ivan Rados. The positioning of the c-arm and the patient during the minimally invasive pain treatment. PERIODICUM BIOLOGORUM 2011; Vol 113, No 2(ISSN0031-5362), pp. 283-289.

16. Levin JH, Wetzel R, Smuck MW. The Importance of Image Guidance during Epidural Injections: Rates of Incorrect Needle Placement during NonImage Guided Epidural Injections. J Spine 2012;1:113. doi:10.4172/2165-7939.1000113.

17. Lawrence Weil, Neal H. Frauwirth, Kasra Amirdelfan, Douglas Grant, Jacob A. Rosenberg. Fluoroscopic Analysis of Lumbar Epidural Contrast Spread After Lumbar Interlaminar Injection. Arch Phys Med Rehabil 2008; Vol 89, pp. 413-416.
Conflict of Interest: Nil

Source of Support: None

\section{How to Cite this Article}

Maulick T, More P | Fluoroscopy Comes to the Rescue in Anaesthesia Management of A Case of Ankylosing Spondylitis | Journal of Anaesthesia and Critical Care Case Reports | January-April 2021; 7(1): 18-21. 